\title{
Frequency and analysis of acute kitchen burn injuries at Allied Hospital, Faisalabad, Pakistan.
}

1. MBBS, M.Phil, Ph.D. Associate Professor Physiology Faisalabad Medical University, Faisalabad, Pakistan.

2. Post Graduate Resident Plastic Surgery Department Allied Burn \& Reconstructive Surgery Center Faisalabad Medical University, Faisalabad, Pakistan.

3. MBBS

House Officer Allied Hospital Faisalabad Medical University, Faisalabad, Pakistan

Correspondence Address: Dr. Qamar Mehboob

Department of Physiology Faisalabad Medical University, Faisalabad, Pakistan.

qamarmehboob89@yahoo.com

Article received on: 07/08/2020

Accepted for publication: 23/12/2020

\begin{abstract}
Qamar Mehboob', Waqar Arif ${ }^{2}$, Sana Arif ${ }^{3}$
ABSTRACT... Objective: To describe the frequency and outcomes of acute kitchen burn patients who were admitted to the burn center. Study Design: Cross Sectional study. Setting: Allied Burn \& Reconstructive Surgery Center, Faisalabad Medical University. Period: August 2019 to August 2020. Material \& Methods: A total of 566 cases were registered. In 293 cases, accident took place in kitchen, 153 cases occurred in home settings, 51 cases occurred at workplace and other 27 cases were in industry. 42 cases were reported at other different places. Results: A total of 566 burn cases occurring at different places including kitchen, home settings, workplace, industry and others, were included in the study. In 293 cases (51.766\%) accidents took place in kitchen. Other 153 cases $(27.03 \%)$ occurred in home settings. 51 cases $(0.9 \%)$ occurred at workplace, 27 cases $(0.45 \%)$ were in industry and 42 other cases $(19.845 \%)$ were in different places. In 2019, total 172 cases were reported. Out of which $113(65.7 \%)$ were males and 59 (34.3\%) were females. In 2020, total 394 cases were reported. Out of which 237 $(60.15 \%)$ were males and $157(39.85 \%)$ were females. All ages and both sexes were included. Our results showed that maximum accidents $(51.766 \%)$ took place in kitchen. Males $(61.84 \%)$ were affected more than females (38.16\%). Regarding age, the group of children (>10) was most to be effected (49\%). Overall statistical analysis for patients was $p<0.046$, $d f=4,95 \% \mathrm{Cl}$. Conclusion: Combined with the previous knowledge, our research work provided great insight into the risk factors and detailed knowledge of burn injuries at different levels especially at home kitchen level.
\end{abstract}

Key words: $\quad$ Burn Injuries, Home Settings, Kitchen.

Article Citation: Mehboob Q, Arif W, Arif S. Frequency and analysis of acute kitchen burn injuries at Allied Hospital, Faisalabad, Pakistan. Professional Med J 2021; 28(9):1297-1301. https://doi.org/10.29309/TPMJ/2021.28.09.5932

\section{INTRODUCTION}

Worldwide, the number of burn cases has increased to such an extent that today it becomes a major cause of injury. ${ }^{1}$ According to World Health Organization (WHO) data, more than 300,000 people die yearly because of fire-related burns. ${ }^{2}$ In another WHO report ${ }^{3}$, burns mainly occur either in the home or at workplace. It is an injury mainly to the skin tissues, caused by direct heat or radiation, electric current and/or any injurious chemical. In thermal burns, hot liquids destroy all or some of body skin tissues. The injuries can be caused by cold, friction, chemical, radiation, heat or electric sources, but most of burn injuries are caused by heat from fire, hot liquids or solids. ${ }^{4}$ Moreover, due to low socioeconomic conditions, underdeveloped countries have more burn cases as compared to the developing countries.
As these cases are open wounds with severe psychological, emotional and economic burden so can cause various types of disabilities and even death. Generally, soon after the injury, an inflammatory response triggers to promote the healing process. $^{5}$ With immediate treatment, these patients require strict follow up including anti-scar therapy and rehabilitation.

Intensive care of a major burn injury patient mostly takes place in a specialized centre. ${ }^{6}$

According to a study reported recently, burn injuries affect mortality and morbidity for at least five to ten years after the injury. ${ }^{7}$

Presently, regarding burn epidemiology, the available data is inconsistent and variable and 
mostly taken from high-income countries. But it can directly access the various health-care systems, their resources and differences in environments. ${ }^{8,9}$ On the other hand in lower income countries, geographical constraints, fewer resources and cost limit data collection, make health care assessment very difficult. ${ }^{10}$

In 2018, Joseph Kimani ${ }^{11}$, found most of the burn cases in $0-4$ yrs group and described that $80 \%$ injuries occurred in home while the remaining occurred either at workplace or any other place. More than $90 \%$ burn cases can be avoided. These patients may die or if survive, they have many psychological effects, and are oftentimes stigmatized or discriminated against.,12 In developed countries, only through prevention strategies like social marketing, legislation, and advocacy $^{12}$, the incidence of burn injuries has been markedly declined.

As compare to other treatments, burn cases face a lot of economic burden. Before treatment, all the burn cases must be evaluated properly. Moreover, in high-income countries, burn injuries are decreasing as compared to its high prevalence elsewhere, with $\sim 90 \%$ of burns occurring in middle and low income countries. ${ }^{13}$ In addition to all these factors, cultural factors such as loose clothing like saris, open-air cooking places, dowry deaths and domestic violence contribute to regional variation. ${ }^{14}$

The incidence of burn injuries varies widely all over the world. Its related deaths/ 100,000 population may be 14.53 in Cote D'lvoire while 0.02 in Malta. ${ }^{15}$ Considering the sex related ratio, males are effected nearly twice as compared to females but in some areas like Ghana and India, females are effected 3 times more than males. ${ }^{16}$ In children $<5$ years of age, mostly scald burns injuries occur which changes to flame-related burns as with increasing age. ${ }^{17}$ So there is a great need to conduct a research project regarding burn injuries to expose their all aspects.

\section{MATERIAL \& METHODS}

It was a cross-sectional study conducted at Plastic Surgery department, Allied Burn \& Reconstructive
Surgery Center, Faisalabad Medical University, Faisalabad, for a period of Aug 2019 - Aug, 2020. After applying the formula:

$$
n=\frac{z_{1-\alpha / 2}^{2} p^{*}(1-p)}{d^{2}}
$$

For calculations of sample size, 566 burn cases occurring at different places including kitchen, home settings, workplace, industry and others, were included in the study. Ethical approval of the research work was taken from Institutional Ethical Review Committee, FMU, Faisalabad (IRB0006912).

\section{Inclusion Criteria}

All acute kitchen burn injuries, irrespective of their age and sex.

\section{Exclusion Criteria}

Patients with post burn complications. Also having any kind of medical problem.

This study was conducted to describe the frequency and outcomes of acute kitchen burn patients who were admitted to the burn center.

\section{RESULTS}

A total of 566 burn cases occurring at different places including kitchen, home settings, workplace, industry and others, were included in the study. In 293 cases (51.766\%) accidents took place in kitchen. Other 153 cases (27.03\%) occurred in home settings. 51 cases (0.9\%) occurred at workplace, 27 cases $(0.45 \%)$ were in industry and 42 other cases (19.845\%) were in different places. Data was entered using and analyzed by using SPSS v.20. Ethical approval was obtained. Overall statistical analysis for patients was $\mathrm{p} \square 0.046$, df $=4,95 \% \mathrm{Cl}$. Our results showed that maximum accidents $(51.766 \%)$ took place in kitchen.

Regarding age and sex, it was an open study and we included cases of all ages and both the sexes. In 2019, total 172 cases were reported. Out of which $113(65.7 \%)$ were males and 59 (34.3\%) were females. In 2020, total 394 cases were reported. Out of which 237 (60.15\%) were 
males and $157(39.85 \%)$ were females (Table-I). Our results showed that males $(61.84 \%)$ were affected more than females (38.16\%).

\begin{tabular}{|l|c|c|c|}
\hline & Male & Female & Total \\
\hline 2019 & 113 & 59 & 172 \\
\hline 2020 & 237 & 157 & 394 \\
\hline Grand Total & & & 566 \\
\hline
\end{tabular}

The age group of children (>10) was most to be effected (49\%) (Table-II).

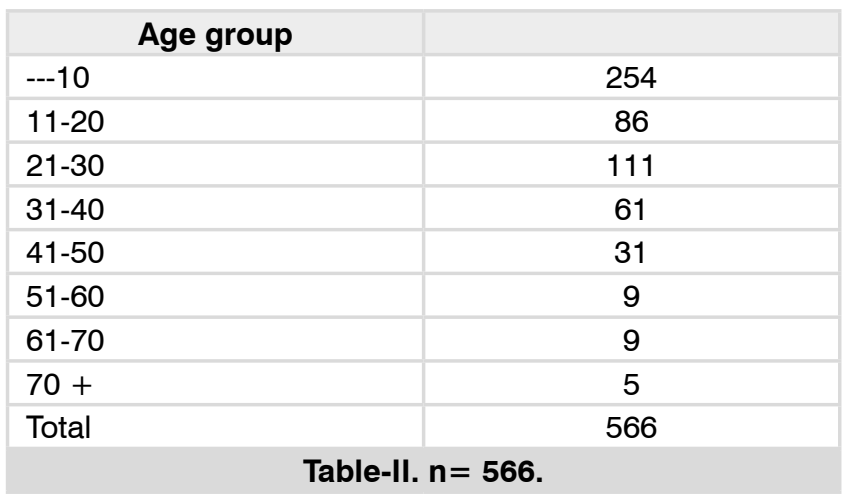

\section{DISCUSSION}

Now-a-days, burn injuries have become a global public health problem, causing an estimated 265,000 deaths world wise ${ }^{18}$ annually. American Burn Association (ABA) reported 450,000 serious burn injuries every year, in United States. ${ }^{19}$

Burn injuries are least-considered injuries that are related with substantial morbidity and mortality. ${ }^{20}$ These injuries, especially severe burns, are followed by an inflammatory and immune response, distributive shock and metabolic changes that may be difficult to manage and may ends on organ failure. Over and above is that these injuries cause damage not only to the physical health, but also to the mental health and life style of the patients as well. Infection burn injury can lead to long-term profound changes that must be treated in best way to optimize the quality of life of these patients.

Based on the mechanism of injury, burn wounds can be classified into 6 different groups: contact burns, fire, scalds, radiation, electrical and chemical. ${ }^{21}$

Thermal injury can be caused by cold such as frostbite. It can be caused by different direct and indirect mechanisms which may lead not only to skin necrosis but also to deep tissue injury. ${ }^{22}$ In our study, we included burn cases occurring at different places including kitchen, other home settings, work places and industries. We found that mostly incidence took place in the kitchen (51.766 \%), mostly caused by milk $26.82 \%$. Our research results were similar to the results reported by Sielu Alemayehu in 2020. ${ }^{18}$ Department of Health and Population of Nepal, also reported high rate of scald injuries $(55,090)$ in the year 2016-2017. ${ }^{23}$

In 2020, management outcome mentioned high incidence of burn injuries in children ${ }^{18}$ and we also found the same results in our study. They also reported that children under two years are being at the highest risk for burns. According to our results children under 10 yrs of age suffered the most (49\%).

We suggest that there is a great need to change burn care for better adjustment to meet the challenges ahead. Data should be collected more accurately for better identification of treatment, prevention and knowledge translation of these injuries. Furthermore, global agencies such as the $\mathrm{WHO}$ and the International Society for Burn Injuries should also come forward. According to a report forwarded by World Health Organization, 2019, they are planning an important checklist initiative that does not require considerable resources for data structuring. ${ }^{24}$ It is the need of the day to adopt new technologies in all phases of the recovery process for further improvement of burn outcomes, ${ }^{20}$ shortly and in the long term as well.

\section{CONCLUSION}

Combined with the previous knowledge collected initially in this study, our research work provided great insight into the risk factors and detailed knowledge of burn injuries at different levels especially at home kitchen level. In future this kind of information will be helpful for the policy and 
programs emphasizing initial prevention as well as acute and chronic treatment of these patients in under developed countries like Pakistan with extremely deficient efforts and low-resource settings.

\section{Copyright $\Subset 23$ Dec, 2020.}

\section{REFERENCES}

1. Haisheng Li,, Zhihui Yao, Jianglin Tan; Epidemiology and outcome analysis of 6325 burn patients: A fiveyear retrospective study in a major burn center in Southwest China, Sci Rep. 2017; 7: 46066.

2. WHO; A WHO plan for burn prevention and care, World Health Organization, 2008.

3. H. Anenden. WHO Report. Burns. 6th March, 2018.

4. American burn association. National Burn Repository 2019 Update, Report of data from 2009-2018 ameriburn, 2019.

5. Stanojcic M, Abdullahi A, Rehou S, Parousis A, Jeschke MG. Pathophysiological response to burn injury in adults. Ann. Surg. 2018; 267: 576-584.

6. Burnett E, Gawaziuk JP, Shek K, Logsetty S. Healthcare resource utilization associated with burns and necrotizing fasciitis. J. Burn Care Res. 2017; 38: e886e891.

7. Mason SA, et al. Increased rate of long-term mortality among burn survivors. Ann. Surg.2019; 269:11921199.

8. Rybarczyk MM, et al. A systematic review of burn injuries in low- and middle-income countries: Epidemiology in the WHO-defined African region. Afr. J. Emerg. Med. 2017; 7:30-37.

9. Sethi J, Gawaziuk JP, Cristall N, Logsetty S. The relationship between income and burn incidence in Winnipeg, Manitoba, Canada: A population health study. J. Burn Care Res. 2018; 39:645-651.

10. Padalko A, Cristall N, Gawaziuk JP, Logsetty S. Social complexity and risk for pediatric burn injury: $A$ systematic review. J. Burn Care Res. 2019; 40:478499.

11. Joseph Kimani Wanjeri, Mary Kinoti, Tom H. A. M. Olewe; Correlation of burn injury and family history of burns among patients hospitalized at a public hospital in Nairobi, Kenya: A case-control study. Indian journal of burns, 2018: 26: 1: 24-28.
12. World Health Organization; Burn prevention - success stories lessons learnt; 2018b, 25 Aug 2018.

13. Greenhalgh DG. Management of burns. N. Engl. J. Med. 2019; 380:2349-2359.

14. Ready FL, et al. Epidemiologic shifts for burn injury in Ethiopia from 2001 to 2016: Implications for public health measures. Burns. 2018; 44:1839-1843.

15. World life expectancy. World Health Ranking, 2017.

16. Bayuo J, Agbenorku P, Amankwa R, Agbenorku M. Epidemiology and outcomes of burn injury among older adults in a Ghanaian tertiary hospital. Burns Open. 2018; 2:98-103.

17. Tegtmeyer LC, et al. Retrospective analysis on thermal injuries in children-demographic, etiological and clinical data of German and Austrian pediatric hospitals 2006-2015-approaching the new German burn registry. Burns. 2018; 44:150-157.

18. Sielu Alemayehu, Bhafta Afera, Kalayou Kidanu, Tilahun Belete. Management Outcome of Burn Injury and Associated Factors among Hospitalized Children at Ayder Referral Hospital, Tigray. Ethiopia, International Journal of Pediatrics / 2020, Feb 2020.

19. Kenny Asselin; National burn awareness week 2020. American Burn Association, Prevention, January 16, 2020.

20. Marc G. Jeschke, Margriet E. van Baar, Mashkoor A. Choudhry; Burn injury, nature public health emergency collection. Nat Rev Dis Primers. 2020; 6(1): 11, Feb, 2020.

21. Joshua Vorstenbosch; Thermal burns. Sept 2019.

22. Nguyen, C. M., Chandler, R., Ratanshi, I. \& Logsetty, S; Handbook of burns. Springer, 2020 (1); 529-547.

23. Kamal Phuyal, Edna Adhiambo Ogada, Richard Bendell, Patricia E Price, Tom Potokar. Burns in Nepal: A participatory, community survey of burn cases and knowledge, attitudes and practices to burn care and prevention in three rural municipalities; BMJ Open 2020; 10: e033071.

24. World Health Organization; Global burn registry; WHO, 2019. 


\begin{tabular}{|c|l|l|l|}
\multicolumn{4}{|c}{ AUTHORSHIP AND CONTRIBUTION DECLARATION } \\
\hline Sr. \# & \multicolumn{1}{|c|}{ Author(s) Full Name } & \multicolumn{1}{c|}{ Contribution to the paper } & Author(s) Signature \\
\hline 1 & Qamar Mehboob & $\begin{array}{l}\text { Analysis \& Compitation of } \\
\text { results. } \\
\text { Data collection. }\end{array}$ \\
\hline 2 & Waqar Arif & Data collection. & \\
3 & Sana Arif & Sama \\
\hline
\end{tabular}

